\title{
$\mathrm{DEA}$ 기법을 이용한 효율적 포트폴리오 구성 방안
}

\author{
손 민 ${ }^{1}$, 신현준 $^{1^{*}}$ \\ ${ }^{1}$ 상명대학교 경영공학과
}

\section{An Efficient Portfolio Selection Methodology using DEA Approach}

\author{
Min Son ${ }^{1}$ and Hyun Joon Shin ${ }^{1 *}$ \\ ${ }^{1}$ Dept. of Management Engineering, Sangmyung University
}

\begin{abstract}
요 약 본 연구에서는 KOSPI에 상장된 기업을 대상으로 기업의 효율성을 고려하여 포트폴리오를 구성하는 방안을 제시한다. 이를 위해 한국거래소(KRX)에서 구분하는 산업 업종별로 DEA(Data Envelopment Analysis) 기법을 이용하 여 기업 효율성 분석을 실시하고 효율성이 우수한 기업들을 대상으로 마코위츠 모형을 통해 포트폴리오를 구성한다. 본 연구에서 제안한 포트폴리오 구성 방안의 성능 실험을 위해 KOSPI에 상장된 약 600개의 기업의 주식을 대상으로 4년 (2007 2010) 동안 매해 포트폴리오를 구성하였고 각각의 포트폴리오 수익률을 경영 효율성을 고려하지 않고 구 성한 포트폴리오 및 시장 수익률과의 비교·분석을 통해 그 우수성을 입증하였다.
\end{abstract}

\begin{abstract}
This study proposes an efficient portfolio selection methodology for the listed corporations in KOSPI with consideration of managerial efficiency. For each industrial sector classified by KRX(Korea Exchange), the proposed method carries out an efficiency analysis using DEA (Data envelopment analysis) approach and for the efficient corporations filtered by DEA, construct portfolio using Markowitz's Model. In order to show the effectiveness of the proposed method, we constructed annually portfolios for 4 years (2007-2010) out of 600 listed corporations in KOSPI and KOSDAQ, and proved that our portfolios are superior to benchmark portfolios in terms of rate of returns.
\end{abstract}

Key Words : DEA, Portfolio Selection, Management Efficiency, Markowitz's portfolio model, KOSPI

\section{1. 서론}

$\mathrm{IMF}$ 이후 금융 시장의 개방 및 3 단계에 걸친 자본자 유화 조치 등으로 인해 국제자본시장의 기능과 규모 등 은 빠르게 확대되고 있다. 이로 인해 국내 경제는 물론 국제 경제가 국내 금융 시장에 미치는 영향은 커지고 있 다. 이처럼 국내 시장이 국제 시장에 노출된다는 것은 국 외의 다양한 금융시장의 리스크에 국내 금융 시장이 크 게 영향을 받고 있다는 것을 의미한다. 실제로 2008년에 일어난 미국의 서브프라임 모기지 사태로 인해 국내 금 융 시장이 크게 흔들린 것을 예로 들 수 있다. 이러한 다 양한 시장변수로 인한 손해를 막기 위해서는 효율적인 투자 전략이 필요하다[3].
효율적인 투자방법으로는 분산투자가 있는데, 분산 투 자를 하기 위함은 투자 위험을 적게 하고, 각 종목들의 위험을 서로 상쇄·완화시키기 위해서이다. 이처럼 분산 투자를 한다는 것 자체를 포트폴리오 구성이라고 볼 수 있는데, 포트폴리오를 구성하는 목적은 안정적인 수익을 얻기 위해서이다. 즉, 현재의 상황과 목적에 맞추어 그 성 과를 최대한 안정적으로 이끌어 내기 위해 포트폴리오 구성이 필요한 것이다.

투자자들은 투자 결정을 그들의 심리나, 투자변수를 고려하여 정성적인 의사결정을 내려 포트폴리오를 구성 한다. 하지만 정성적인 의사결정 보다 구성된 종목들 간 의 상관관계를 최소화할 수 있는 마코위츠 모형 (Markowitz's model)을 활용하여 정량적인 의사결정을 내 려 포트폴리오를 구성하는 것이 투자자에게 더 유리하다.

${ }^{*}$ Corresponding Author : Hyun Joon Shin

Tel: +82-10-7148-6786 email: hjshin@smu.ac.kr

접수일 12년 01월 25일 수정일 (1차 12년 03월 13일, 2차 12년 03월 27일)

게재확정일 12 년 04 월 12 일 
그러나 이모형은 종목들의 주가에만 의존하기 때문에 기 업들의 경영 효율성을 고려할 수 없다는 단점이 있다. 또 한 기존 포트폴리오 구성방법에서는 기업들의 경영 효율 성을 고려한 사례를 찾아보기가 어렵다. 따라서 본 연구 에서는 기업의 경영 효율성을 고려하여 포트폴리오를 구 성하기 위해 경영과학 분야의 DEA 기법을 이용한 포트 폴리오 구성 방법론을 제시하고자 한다.

본 논문은 다음과 같이 구성된다. 2장에서는 $\mathrm{DEA}$ 기 법과 마코위츠 모형을 결합한 포트폴리오 구성 전략에 대해 설명한다. 3장에서는 KOSPI에 상장된 기업들의 주 가와 재무 데이터를 이용하여 구성한 포트폴리오 수익률 과 성과를 기술하며 마지막으로 4장에서는 결론을 제시 한다.

\section{2. 포트폴리오 선택 전략}

자산의 위험을 최소화하기 위해서 구성하는 포트폴리 오는 체계적인 위험(systemic risk)과 비체계적인 위험 (unsystemic risk)에 노출된다. 체계적인 위험, 즉 경기의 침체와 시장의 불안으로 인해 피할 수 없는 위험과는 다 르게 비체계적인 위험은 금융 시장과는 무관하게 계별 종목들의 변동 요인에 의해 발생하기 때문에 효율적인 포트폴리오를 구성함으로써 위험을 최소화할 수 있다[3].

일반적으로 포트폴리오를 구성하기 위해서 구성된 종 목들 간의 상관관계를 최소화할 수 있는 마코위츠 모형 (Markowitz's model)을 활용한다. 그러나 마코위츠 모형 은 종목들의 과거 주가에만 의존하여 포트폴리오를 구성 하기 때문에 기업들의 경영 효율성 등을 고려할 수 없다 는 한계점이 있다.

따라서 본 장에서는 기업의 경영 효율성을 고려하여 포트폴리오를 구성하기 위해 경영과학 분야의 DEA 기법 과 마코위츠 모형을 결합한 포트폴리오 구성 방법론을 제시하고자 한다.

\subsection{DEA 기법을 이용한 경영 효율성 평가}

자료포락분석(Data Envelopment Analysis; 이하 DEA) 은 1978년 Charnes, Cooper \& Rhodes에 의해 제안되어 복수투입과 복수산출에 관한 비율모형으로 의사결정 대 안에 대한 효율성 정도를 파악하는데 매우 유용하다. 이 기법은 투입요소와 산출요소를 사용하여 동일하거나 매 우 유사한 기능을 수행하는 의사결정단위(Decision Making Unit; 이하 DMU) 또는 조직단위의 상대적 효율 성을 측정하고 평가하는데 사용 할 수 있는 방법론이다.
[표 1] 투입 및 산출 요소

[Table 1] Input and output elements

\begin{tabular}{|c|c|c|c|}
\hline & 업종 & 투입요소 & 산출요소 \\
\hline \multirow{12}{*}{$\begin{array}{l}\text { 제 } \\
\text { 조 } \\
\text { 업 }\end{array}$} & 음식료 & \multirow{17}{*}{$\begin{array}{c}\text { 자산총계, } \\
\text { 매출원가, } \\
\text { 판관비 }\end{array}$} & \multirow{19}{*}{ 매출액 } \\
\hline & 섬유의복 & & \\
\hline & 종이목재 & & \\
\hline & 화학 & & \\
\hline & 의약품 & & \\
\hline & 비금속 & & \\
\hline & 철강금속 & & \\
\hline & 기계 & & \\
\hline & 전기전자 & & \\
\hline & 의료정밀 & & \\
\hline & 운수장비 & & \\
\hline & 기타 & & \\
\hline \multicolumn{2}{|r|}{ 유통 } & & \\
\hline \multicolumn{2}{|c|}{ 전기가스 } & & \\
\hline \multicolumn{2}{|r|}{ 건설 } & & \\
\hline \multicolumn{2}{|c|}{ 운수창고 } & & \\
\hline \multicolumn{2}{|c|}{ 서비스 } & & \\
\hline \multicolumn{2}{|r|}{ 통신 } & $\begin{array}{c}\text { 자산총계, } \\
\text { 영업이익, } \\
\text { 판관비 }\end{array}$ & \\
\hline \multirow{3}{*}{$\begin{array}{l}\text { 금 } \\
\text { 융 } \\
\text { 업 }\end{array}$} & 은행 & $\begin{array}{c}\text { 자산총계, } \\
\text { 매출원가, } \\
\text { 판관비 }\end{array}$ & \\
\hline & 증권 & $\begin{array}{c}\text { 수수료비용, } \\
\text { 유가증권평가 및 } \\
\text { 처분손실, } \\
\text { 이자비용, } \\
\text { 판관비, 자산 }\end{array}$ & \multirow[t]{2}{*}{ 영업수익 } \\
\hline & 보험 & $\begin{array}{l}\text { 보험금비용, } \\
\text { 유지비, 자산 }\end{array}$ & \\
\hline
\end{tabular}

$\mathrm{DEA}$ 모형을 통한 효율성 평가를 실시함에 있어서 가 장 중요한 요소 중 하나는 투입 및 산출요소의 선정에 있 다. 본 연구에서는 선행연구를 통해서 표 1 과 같이 업종 별로 투입 및 산출요소를 선정한다. 또한 $\mathrm{DEA}$ 모형을 통 한 효율성 평가를 위해서 평가 하고자 하는 업종들의 대 상은 같은 산업 군으로 제한을 둔다.

경영 효율성을 분석할 수 있는 $\mathrm{DEA}$ 모형에는 $\mathrm{CCR}$ (Charnes-Cooper-Rhodes), BCC(Banker-Charnes-Cooper), 가변형 모형(additive model), 슬랙 중심 측정모형(slacksbased measure) 등 많은 종류가 개발되었다[4]. 본 논문에 서는 규모수익성(Return to Scale; RTS)이 일정하다고 가 정한 $\mathrm{CCR}$ 모형을 기반으로 실험을 실시하고자 하며 투 입중심 $\mathrm{CCR}$ 모형을 선형계획모형으로 정리하면 다음과 같다[6].

$$
\begin{array}{ll}
\text { Minimize } & \theta \\
\text { subject to } & \theta x_{0}-X \lambda \geq 0 \\
& y_{0}-Y \lambda \leq 0
\end{array}
$$




$$
\lambda \geq 0
$$

Notations :

$\theta \quad \mathrm{DMU}_{0}$ 의 투입물 승수

$x_{0}, y_{0} \quad \mathrm{DMU}_{0}$ 의 투입물과 산출물 벡터

$X, Y$ 전체 $\mathrm{DMU}$ 들의 투입물과 산출물 행렬

$\lambda$ 가중치 열 벡터

본 연구에서는 경영 효율성이 우수한 기업들을 대상으 로 포트폴리오를 구성하기 위해 위 식 (1) (4)를 바탕으 로 업종별로 $\mathrm{DEA}$ 경영 효율성 분석을 통해 산출된 효율 성 값이 0.9 이상인 기업들을 선정한다.

\section{2 마코위츠 모형을 이용한 포트폴리오 선택 전략}

마코위츠 포트폴리오 선정모형은 비선형계획모형 (nonlinear programming model)으로 일정한 수익률 제약 하에 자산 간의 상관계수가 낮은 종목을 포트폴리오에 포함함으로써 안정적이고 효율적 포트폴리오를 구성하는 것을 기본 개념으로 한다[5]. 마코위츠 모형은 위험의 수 준을 나타내는 개별 종목 수익률들 간의 공분산을 최소 화하는 것을 목적함수로 한다. 더불어 기본적으로 '공매 도가 존재하지 않는다.'는 가정 하에 투자자가 요구하는 최소기대수익률을 달성해야 하고, 투자가 가능한 금액을 모두 포트폴리오에 투자해야 한다는 제약조건이 따른다 [3]. 본 논문에서 사용하는 마코위츠 모형은 다음과 같다.

$$
\begin{array}{ll}
\text { Minimize } & \sum_{i=1}^{N} \sum_{j=1}^{N} w_{i} w_{j} \sigma_{i j} \\
\text { subject to } & \sum_{j=1}^{N} \mu_{j} w_{j} \geq K \\
& \sum_{j=1}^{N} w_{j}=1
\end{array}
$$

Notation :

$N$ 전체 종목 수

$\mu_{j}$ 주식 $j$ 의 평균수익률 $(j=1,2, \cdots, N)$

$\sigma_{i j}$ 주식 $i$ 수익률과 주식 $j$ 수익률 간의 공분산

$K$ 포트폴리오에 요구되는 최소 기대수익률

$w_{j}$ 포트폴리오에서 주식 $j$ 의 구성 비율

식 (5)는 목적함수로써 포트폴리오를 구성할 종목들 간의 수익률의 공분산을 최소로 하기 위한 식이다. 즉 포 트폴리오에 투자 위험을 최소로 할 수 있는 종목들을 포
함시킴과 동시에 식 (6)에서는 기대수익률을 $K$ 이상으로 제약한다. 식 (7)은 투자 원금의 모두를 포트폴리오에 투 자한다는 제약식이다.

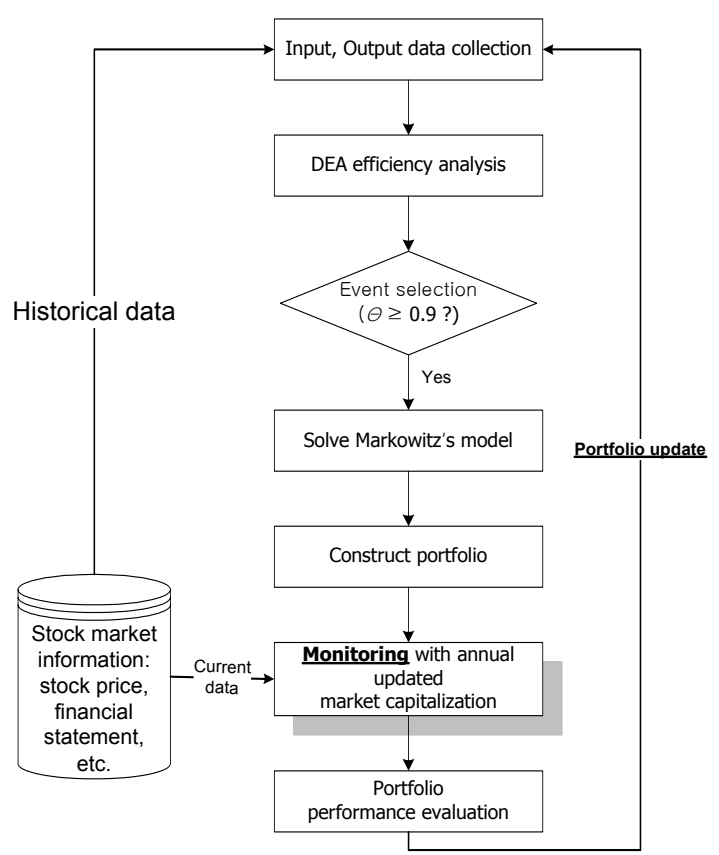

[그림 1] 포트폴리오 선택 전략

[Fig. 1] Portfolio selection strategy

본 장에서 설명한 $\mathrm{DEA}$ 기법과 마코위츠를 결합한 포 트폴리오 구성 전략을 순서도로 정리하면 그림 1 과 같다.

\section{3. 실험 결과 및 분석}

\section{1 실험 데이터 및 실험 계획}

포트폴리오 구성을 위해 KOSPI에 상장된 종목 중에 서 우선주 종목과 ETF(Exchange Traded Funds) 종목 등 을 제외한 약 600 개의 종목을 대상으로 실험하였다. 포트 폴리오 구성 기간은 2007년부터 2010년까지이며 표 2는 본 연구의 실험 데이터와 실험 계획에 대한 설명이다.

본 연구에서 제시하는 $\mathrm{DEA}$ 기법을 이용한 포트폴리오 구성 방안은 전년도 수집 요인을 바탕으로 다음년도 포 트폴리오를 구성하는 방식으로 실험을 실시하였다. 예컨 대 2007년 초에 포트폴리오를 구성하기 위해서 2006년 한 해 동안의 투입 요소와 산출 요소를 이용하여 경영 효 율성을 평가하였다. DEA 기법을 통한 업종별 효율성은 Frontier Analyst 4.0을 이용하여 분석하였고, 마코위츠 모 
형의 해는 LINGO 10.0 프로그램을 이용하여 구하였다.

[표 2] 실험 데이터 및 실험 계획

[Table 2] Experimental data and experimental design

\begin{tabular}{|c|c|}
\hline 대상 & KOSPI에 상장된 약 600 개의 기업 \\
\hline 기간 & 2007년부터 2010년까지 \\
\hline 평가 주기 & $\begin{array}{c}1 \text { 회/년 } \\
\text { (연초 포트폴리오 구성 후, 연말 평가) }\end{array}$ \\
\hline 성과 측정 & $\begin{array}{c}\text { 벤치마크 대비 포트폴리오 수익률, } \\
\text { 샤프지수, 젠센의 알파, IR, 그룹 별 수익률 } \\
\text { 변동성 }\end{array}$ \\
\hline 자료 수집 & 이데일리 MARKETPOINT \\
\hline
\end{tabular}

본 연구에서는 마코위츠 모형을 통해 구성한 포트폴리 오와 DEA와 마코위츠 모형을 결합하여 구성한 포트폴리 오, 그리고 동일한 기간만큼의 KOSPI 시장 수익률을 산 출하여 비교 분석하였다. 편의를 위해 DEA와 마코위츠 모형을 이용한 포트폴리오 구성 전략을 $P M_{D E A \_M Q}$ 로 마 코위츠 모형만을 이용한 포트폴리오 구성 전략을 $P M_{M Q}$ 로 표현하였다.

\section{2 포트폴리오 수익률 분석}

표 3은 각 업종별로 $\mathrm{DEA}$ 기법을 통해 효율성이 $90 \%$ 이내인 것들로 선별된 종목 수와 선별된 종목을 바탕으 로 마코위츠를 통해 최종 포트폴리오를 구성한 종목 수 를 나타내고 있다.

$\mathrm{KOSPI}$ 에 상장된 종목 중에서 우선주 종목과 ETF(Exchange Traded Funds) 종목 등을 제외한 약 600개 인 종목 수에서 마코위츠 모형을 통해 포트폴리오를 구 성하기 전에 $\mathrm{DEA}$ 를 통해 효율성이 $90 \%$ 이내인 것을 선 별함으로써 대략 반으로 종목의 수를 축소할 수 있었다.

[표 3] 포트폴리오 구성

[Table 3] Construction of portfolios

\begin{tabular}{|c|c|c|c|}
\hline 년도 & $\begin{array}{c}\text { KOSPI } \\
\text { 상장 종목 }\end{array}$ & $\begin{array}{c}\text { 효율성 } \\
0.9 \text { 이상 }\end{array}$ & $P M_{D E A \_M Q}$ \\
\hline 2007 & 603 개 & 365 개 & 21 개 \\
\hline 2008 & 611 개 & 359 개 & 36 개 \\
\hline 2009 & 611 개 & 344 개 & 20 개 \\
\hline 2010 & 611 개 & 373 개 & 43 개 \\
\hline
\end{tabular}

표 4는 2007년부터 2010년까지 본 연구에서 제시하는 $P M_{D E A_{-} M Q}$ 수익률과 비교 대상인 $P M_{M Q}$ 수익률, 그리 고 동일 기간 벤치마크 수익률을 비교하고 있다. 포트폴
리오의 수익률은 시가총액을 기준으로 가중 평균을 하여 산출하였고, 벤치마크는 포트폴리오 구성 및 갱신 시점과 동일한 기간으로 KOSPI 지수의 단순수익률을 사용하였 다. 2009년을 제외하고 $P M_{D E A_{-} M Q}$ 방법론의 포트폴리오 수익률이 $P M_{M Q}$ 방법론과 벤치마크 수익률보다 우수한 것을 볼 수 있다. 2008년도에는 서브프라임 모기지(sub prime mortgage)사태로 인한 금융 시장의 불황으로 수익 률이 전반적으로 저조하지만 같은 년도의 $P M_{M Q}$ 의 수익 률과 벤치마크 수익률에 비해서 $P M_{D E A_{-} M Q}$ 의 수익률이 덜 저조한 것을 볼 수 있다.

[표 4] 년도 별 수익률 비교

[Table 4] Comparison of rate of return by year

\begin{tabular}{|c|c|c|c|}
\hline 년도 & $P M_{D E A \perp M Q}$ & $P M_{M Q}$ & 벤치마크 \\
\hline 2007 & $38 \%$ & $33 \%$ & $32 \%$ \\
\hline 2008 & $-26 \%$ & $-35 \%$ & $-39 \%$ \\
\hline 2009 & $35 \%$ & $17 \%$ & $45 \%$ \\
\hline 2010 & $46 \%$ & $29 \%$ & $21 \%$ \\
\hline
\end{tabular}

그림 2는 표 4에서 $P M_{D E A_{-} M Q}$ 의 포트폴리오 수익률 과 $P M_{M Q}$ 의 포트폴리오 수익률, 그리고 벤치마크 수익 률을 연도별로 나타낸 그림이다. 2009년도를 제외하고는 $P M_{D E A} M Q$ 의 수익률이 보다 더 우수한 것을 알 수 있었 다. 또한 금융 시장이 불황이었던 2008년에는 $P M_{D E A_{-} M Q}$ 의 수익률이 벤치마크 수익률에 비해 약 $13 \%$ 더 적은 손실을 보았음을 알 수 있다.

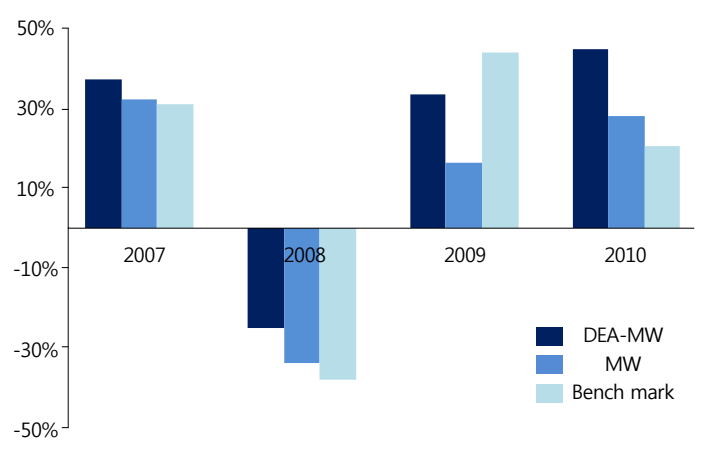

[그림 2] $P M_{D E A \_M Q}$ 와 벤치마크들 간의 수익률 비교

[Fig. 2] Comparison between $P M_{D E A_{-} M Q}$ and benchmarks

\section{3 포트폴리오 성과 측정}

일반적으로 포트폴리오 성과 측정을 위한 도구로 수익 
률의 변동성, 샤프지수와 젠센의 알파 그리고 IR이 있다. 샤프지수는 포트폴리오의 위험 1 단위에 대한 초과 수익 의 정도를 나타내는 지표, 즉 초과 수익이 얼마인가를 측 정하는 지표이고 모형은 식(8)과 같다.

$$
\text { Sharpe Ratio }=\frac{R_{i}-R_{f}}{\sigma_{i}}
$$

Notations :

$$
\begin{array}{ll}
R_{i} & \text { 포트폴리오 } i \text { 의 수익률 } \\
R_{f} & \text { 무위험 수익률(국고채 } 3 \text { 년 만기) } \\
\sigma_{f} & \text { 포트폴리오 } i \text { 의 표준편차 }
\end{array}
$$

젠센의 알파는 포트폴리오의 수익률이 균형 상태에서 의 수익률보다 얼마나 높은지를 나타내는 지표, 즉 포트 폴리오 수익률에서 기대 수익률을 뺀 값을 의미하며 모 형은 식(9)와 같다.

젠센의 알파 $=\left(R_{i}-R_{f}\right)-b_{p}^{*}\left(K_{i}-R_{f}\right)$

Notations :

$b_{p} \quad$ 포트폴리오의 베타

$K_{i} \quad$ 시장 수익률

그리고 IR은 포트폴리오 관리자의 능력을 측정할 수 있는 지표로 포트폴리오의 초과 수익률을 추적 오차로 나눈 값을 말하며 RVR(Reward-to-Variability Ratio)라고 도 부른다. 세 가지 모두 측정 된 결과 값이 높을수록 투 자 성과가 우수하다고 할 수 있으며 IR의 경우에는 실무 적으로 미국에서는 $50 \%$ 이내인 경우에 '우수'한 것으로 평가한다. IR의 산출 모형은 식(10)과 같다.

$$
I R=\frac{\left(R_{i}-K_{i}\right)}{T e}
$$

Notations :

$T e \quad$ 추적 오차의 표준편차

[표 5] 포트폴리오 성과 측정

[Table 5] Portfolio Performance Measurement

\begin{tabular}{|c|c|c|c|c|}
\hline & 변동성 & $\begin{array}{c}\text { 샤프 } \\
\text { 지수 }\end{array}$ & $\begin{array}{c}\text { 젠센의 } \\
\text { 알파 }\end{array}$ & $\mathrm{IR}$ \\
\hline$P M_{D E A \_M Q}$ & $33 \%$ & $57 \%$ & $12 \%$ & $26 \%$ \\
\hline$P M_{M Q}$ & $31 \%$ & $21 \%$ & $1 \%$ & $-12 \%$ \\
\hline
\end{tabular}

표 5는 $P M_{D E A_{-} M Q}$ 와 $P M_{M Q}$ 의 포트폴리오를 성과 측 정한 결과 값을 나타내고 있다. 샤프지수와 젠센의 알파 그리고 IR 모두 성과 측정값이 높을수록 우수한 포트폴 리오라고 정의한다.

상대적으로 $P M_{D E A_{-} M Q}$ 의 포트폴리오가 $P M_{M Q}$ 포트 폴리오의 성과에 비해 우수한 것을 볼 수 있다.

\section{4. 결론}

본 연구에서는 KOSPI에 상장된 기업을 대상으로 $\mathrm{DEA}$ 기법을 이용하여 업종별로 기업의 효율성이 우수한 기업들을 선정하고, 선정된 기업들에 대해서 마코위츠 모 형을 이용하여 포트폴리오를 구성하는 2 단계 방안을 제 시하였다. 이를 통해 과거 수익률과 공분산 데이터에만 의존하는 기존 마코위츠 모형의 한계점을 보완하고 포트 폴리오의 성능을 다양한 포트폴리오 평가척도 측면에서 높일 수 있었음을 실험을 통해 보였다. 특히 기업 효율성 을 고려한 포트폴리오 구성 방안은 경영 효율성이 부실 한 기업을 포트폴리오 구성 조건에서 제외시켜줌으로써 기존의 마코위츠 포트폴리오 구성 방안보다 수익률을 향 상시킬 수 있다는 것을 알 수 있었다. 또한 포트폴리오 구성 전략을 위해 DEA 및 마코위츠 모형 등을 이용한 경 영과학적 접근방법은 실무적으로 투자관리 및 분석에 있 어 정량적인 판단을 지원함으로써 금융 기관의 펀드 운 용 시 유용한 지표로 사용될 수 있을 뿐만 아니라, 학문 적으로도 블랙리터만 모형과 함께 섹터 펀드를 설계하기 위한 최적화 모형의 기반이 될 수 있을 것으로 기대한다.

\section{Reference}

[1] Chang, Jo Young, "Study on Logistic Efficiency of Third Party Logistic by DEA-AHP method", The Graduate School, Yonsei University, 2008.

[2] Da-Young Choi, Beum Jun Ahn, Hyun Joon Shin, "Portfolio Selection Strategy with Consideration of Growth Potential of Corporations", The Korea Academia-Industrial cooperation Society, Vol.12, No.9, pp.3849-3855, 2011.

[3] Jae Pil Ryu, "A Study on Optimizing Portfolio Management using Inventory Control Methodology", The Graduate School, Sangmyung University, 2011.

[4] JongKi Kim, DaYeon Kang, "Measuring Efficiency of Korean Apartment Construction Firms using DEA", The 
Korea Contents Association, Vol.8, No.7, pp.201-207, 2008.

[5] Markowitz, H. M. (1952), Portfolio Selection, Journal of Finance, 7(1), 77-91.

[6] Myung-Hee Chang, "Relative Efficiency of Korea Trucking Transport Business Using DEA Model", The Korea Contents Association, Vol.10, No.12, pp.328-341, 2010.

민(Min Son)

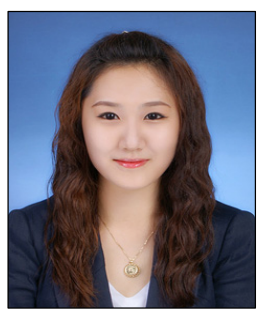

<관심분야>

금융공학, 생산관리
[준회원]

- 2011년 8월 : 상명대학교 경영공 학과(공학사)

- 2011년 8월 현재: 상명대학교 경영공학과 석사과정

\section{신 현 준(Hyun Joon Shin)}

[종신회원]

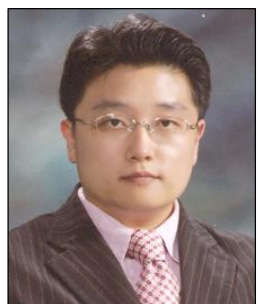

- 1995년 2월 : 고려대학교 산업공 학과(공학사)

- 1997년 2월 : 고려대학교 산업공 학과(공학석사)

- 2002년 2월 : 고려대학교 산업공 학과(공학박사)

- 2002년 5월 2004년 4월: 미국 Texas A\&M대학교 연구원

- 2004년 6월 2005년 2월: (주)삼성전자 책임연구원

- 2005년 3월 현재 : 상명대학교 경영공학과 부교수

<관심분야>

금융공학, 최적화, 생산관리, 공급사슬망관리 